\title{
Estimation of genetic parameters for novel functional traits in Brown Swiss cattle
}

\author{
M. Kramer, ${ }^{* 1}$ M. Erbe, ${ }^{*}$ B. Bapst, $†$ A. Bieber, $\ddagger$ and H. Simianer* \\ *Department of Animal Science, Animal Breeding and Genetics Group, Georg-August-Universität Göttingen, Albrecht-Thaer-Weg 3 , \\ 37075 Göttingen, Germany \\ †Qualitas AG, Chamerstraße 56, 6300 Zug, Switzerland \\ $\ddagger \mathrm{FiBL}$, Research Institute of Organic Agriculture, Ackerstrasse, 5070 Frick, Switzerland
}

\begin{abstract}
The aim of this study was to estimate genetic parameters and accuracies of breeding values for a set of functional, behavior, and conformation traits in Brown Swiss cattle. These traits were milking speed, udder depth, position of labia, rank order in herd, general temperament, aggressiveness, milking temperament, and days to first heat. Data of 1,799 phenotyped Brown Swiss cows from 40 Swiss dairy herds were analyzed taking the complete pedigree into account. Estimated heritabilities were within the ranges reported in literature, with results at the high end of the reported values for some traits (e.g., milking speed: $0.42 \pm 0.06$, udder depth: $0.42 \pm 0.06$ ), whereas other traits were of low heritability and heritability estimates were of low accuracy (e.g., milking temperament: $0.04 \pm 0.04$, days to first heat: $0.02 \pm 0.04$ ). For most behavior traits, we found relatively high heritabilities (general temperament: $0.38 \pm 0.07$, aggressiveness: $0.12 \pm 0.08$, and rank order in herd: $0.16 \pm 0.06)$. Position of labia, arguably an indicator trait for pathological urovagina, was genetically analyzed in this study for the first time, and a moderate heritability $(0.28 \pm 0.06)$ was estimated.
\end{abstract}

Key words: genetic parameter, accuracy of breeding value, behavior, conformation

\section{INTRODUCTION}

Although dairy cattle breeding in the past largely focused on production traits, functional aspects such as udder health, milking speed, or behavioral traits are becoming increasingly important, both from an economic and an animal welfare point of view. In the conventional breeding scheme it is often costly and time consuming to collect sufficient numbers of daughter records for a wide range of functional traits to obtain daughter-based sire predictions with sufficient accu-

Received October 5, 2012.

Accepted June 7, 2013.

${ }^{1}$ Corresponding author: mkramer@gwdg.de racy. Many functional traits have a low heritability, are difficult or expensive to measure, or are expressed late in life only. Because of the currently high relevance of functional traits, it might be appropriate to consider the possibility of integrating new phenotypic traits related to behavior, health, conformation, and fertility into modern dairy cattle breeding programs. For implementing these new traits into a routine breeding value estimation, it is important to make phenotyping as cost effective as possible and ensure that recording does not disturb the working routine on a dairy farm. Therefore, we considered it important to cover a wide range of traits that were described in different ways (scoring by farmers, scoring by experts, exact measurement of conformation) and to use simple scales that could be applied by the farmer or simple, less expensive tools for measurement.

\section{Heritability of Behavioral Traits}

Behavior traits represent an important functional trait complex. As shown by Sewalem et al. (2010), behavioral traits and docility of a cow significantly influence her productivity and longevity. The authors found that Holstein cows described as very nervous were $18 \%$ more likely to be culled than Holstein cows of average temperament, whereas cows classified as very calm had a $7 \%$ lower risk of being culled than the average. Despite this high importance of behavioral traits in dairy cattle, most behavior studies in cattle deal with beef cattle (e.g., Le Neindre et al., 1995; Hoppe et al., 2010). Schutz and Pajor (2001) noted that work on temperament and behavior in dairy cattle is limited. In the last decades, different studies have estimated heritabilities for traits that describe behavior and temperament traits of dairy cows. Heritability estimates together with the characteristics of these studies are summarized in Table 1. In general, many different traits have been used to describe behavior and docility of cattle. Heritability estimates of these traits were in a wide range (0.07-0.53) but were mostly moderate to low. 


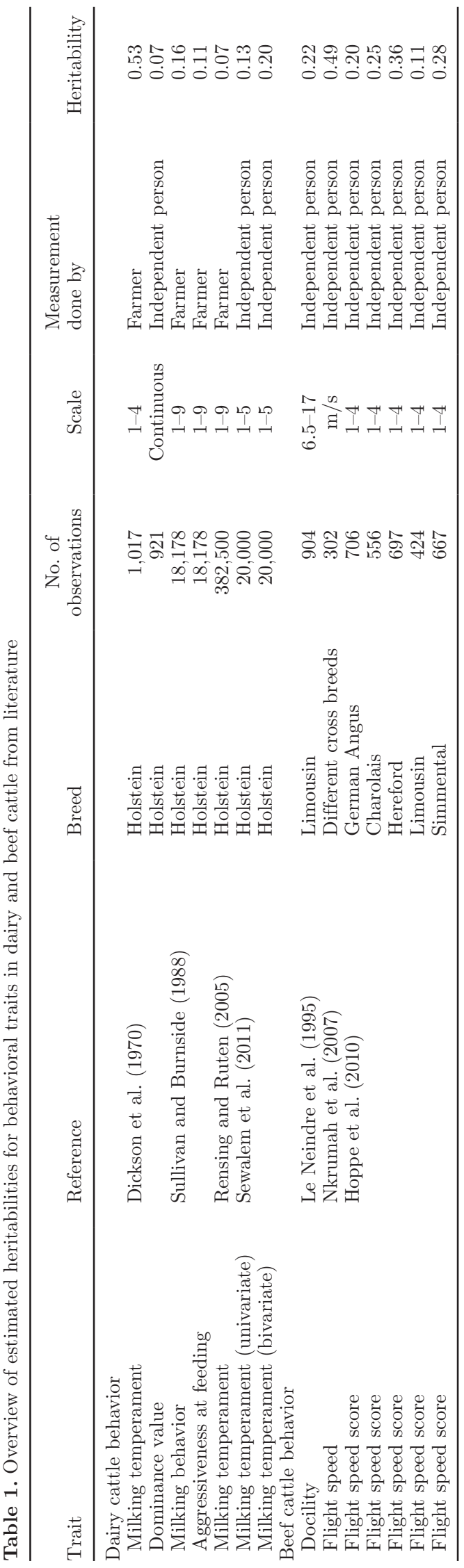

\section{Heritability of Milking Speed}

Another important functional trait is milking speed. Sewalem et al. (2010) described the importance of milking speed in 2 different ways. On the one hand, very slow milking cows disturb the flow of cows through the milking parlor and thus increase production costs due to increased labor costs. On the other hand, Rupp and Boichard (1999) found that very fast milking cows tend to have a high SCS and so have a higher risk of being affected by mastitis or ultimately being culled. Hence milking speed is considered as a trait with an intermediate optimum in the range of about $2 \mathrm{~kg} / \mathrm{min}$ (Winter, 2009). In principle, milking speed of a cow can be measured by using 2 different methods. The first method is a subjective scoring, mostly done by farmers on a scale from 1 to 5 or 1 to 9 . Subjectively scored milking speed is a trait with low to moderate heritability (e.g., Rupp and Boichard, 1999; Rensing and Ruten, 2005; Table 2). The other method is an objective measurement in kilograms per minute (during the complete milking event or only in the main milking phase). When objectively assessed, milking speed is a trait with moderate to high heritability (e.g., Lassen and Mark, 2008; Table 2).

\section{Heritability of Conformation Traits}

One conformation trait that influences udder health is udder depth. This trait is defined as the distance between the base of udder and the hock or ground. Seykora and McDaniel (1985) found a significantly $(P$ $<0.01)$ higher SCC in cows with low udder depth, and the older the cow, the stronger the effect. Most studies that estimated genetic parameters for conformation traits used a scale of 1 to 9 to score udder depth and found moderate heritabilities (e.g., Neuenschwander et al., 2005; Table 2). Heritability of udder depth was found to be higher when objective measurements (in centimeters) were used (Seykora and McDaniel, 1985; Table 2).

A novel trait that is linked to fertility is position of labia (Bühler and Maurer, 2004). As explained by F. Schmitz-Hsu (Swissgenetics, Zollikofen, Switzerland; personal communication), the position of the labia is highly correlated with urovagina, which in turn has a significant influence on fertility. Gautam and Nakao (2009) found that $15.4 \%$ of cows from 7 herds had clinically relevant urovagina. These cows required more inseminations to get pregnant ( 5 vs. $2 ; P<0.001$ ), had more days open (370 vs. $136 ; P<0.001)$, and were at higher risk of endometritis $(36.4$ vs. $9.2 \% ; P$ $<0.001)$ than cows without urovagina. Bühler and Maurer (2004) noted that more dairy cattle than beef 
Table 2. Overview of estimated heritabilities for milking speed, udder depth, and interval from calving to first insemination traits in dairy cattle from literature

\begin{tabular}{|c|c|c|c|c|c|c|}
\hline Trait & Reference & Breed & $\begin{array}{c}\text { No. of } \\
\text { observations }\end{array}$ & Scale & $\begin{array}{l}\text { Measurement } \\
\text { done by }\end{array}$ & Heritability \\
\hline \multicolumn{7}{|l|}{ Measurement of milking speed } \\
\hline Milking speed & Meyer and Burnside (1987) & Holstein/Ayrshire & 550,422 & $1-5$ & Farmer & 0.21 \\
\hline Milking speed & Boettcher et al. (1998) & Holstein & 250,000 & $1-5$ & Farmer & 0.15 \\
\hline Milking speed & Rupp and Boichard (1999) & Holstein & 29,284 & $1-5$ & Farmer & 0.17 \\
\hline Milking speed & Ilahi and Kadarmideen (2004) & $\begin{array}{l}\text { Brown Swiss, } \\
\text { Simmental, } \\
\text { Holstein }\end{array}$ & 900,628 & $1-5$ & Independent person & 0.25 \\
\hline Milking speed & & Brown Swiss & 204,397 & $\mathrm{~kg} / \mathrm{min}$ & & 0.46 \\
\hline Milking speed & & Simmental & 655,989 & $\mathrm{~kg} / \mathrm{min}$ & & 0.48 \\
\hline Milking speed & Rensing and Ruten (2005) & Holstein & 382,500 & $1-9$ & Farmer & 0.10 \\
\hline Milking speed & & Holstein & $1,608,800$ & $\mathrm{~kg} / \mathrm{min}$ & & 0.28 \\
\hline Milking speed: freestalls & Lassen and Mark (2008) & Holstein & 19,347 & $1-9$ & Farmer & 0.29 \\
\hline Milking speed: tiestalls & & Holstein & 10,843 & $1-9$ & Farmer & 0.35 \\
\hline Milking speed: Baden-Würtemberg & & Simmental & 26,751 & $\mathrm{~kg} / \mathrm{min}$ & & 0.37 \\
\hline Milking speed: Bavaria & & Simmental & 35,555 & $\mathrm{~kg} / \mathrm{min}$ & & 0.28 \\
\hline \multicolumn{7}{|l|}{ Measurement of udder depth } \\
\hline Udder height & Seykora and McDaniel (1985) & Holstein & 898 & $\mathrm{~cm}$ & & 0.52 \\
\hline Udder depth & Neuenschwander et al. (2005) & Holstein & 42,807 & $1-9$ & & 0.29 \\
\hline Udder depth: freestall & Lassen and Mark (2008) & Holstein & 19,347 & $1-9$ & & 0.37 \\
\hline Udder depth: tiestall & & Holstein & 10,843 & $1-9$ & & 0.46 \\
\hline Udder depth & Interbull (2012) & Brown Swiss & $\begin{array}{l}\text { All cows } \\
\text { with linear } \\
\text { description } \\
\text { since } 1994\end{array}$ & $1-9$ & Independent person & 0.32 \\
\hline \multicolumn{7}{|c|}{ Measurement of interval from calving to insemination } \\
\hline Interval calving to first insemination & Royal et al. (2002) & Holstein & 1,080 & Days & & 0.11 \\
\hline $\begin{array}{l}\text { Commencement of luteal activity postpartum } \\
\text { (progesterone content) }\end{array}$ & & Holstein & 1,212 & Days & & 0.16 \\
\hline Interval calving to first insemination & Berry et al. (2003) & Holstein & 8,591 & Days & & 0.02 \\
\hline Interval calving to first insemination & Andersen-Ranberg et al. (2005) & Norwegian Red & $1,815,581$ & Days & & 0.03 \\
\hline Interval calving to first insemination & König et al. (2008) & Holstein & 73,344 & Days & & 0.07 \\
\hline Days to first detectable estrus (activity) & Løvendahl and Chagunda (2009) & $\begin{array}{l}\text { Holstein, Jersey, } \\
\text { Red Dane }\end{array}$ & 515 & Days & & $0.10-0.18$ \\
\hline Interval from calving to first insemination & Interbull (2012) & Brown Swiss & $\begin{array}{l}\text { All AI data } \\
\text { since } 1994\end{array}$ & Days & & 0.04 \\
\hline
\end{tabular}

(o insemination Interval calving to first insemination

(progesterone content)

Holstein

since 199 
cattle cows showed pathologic position of urovagina. As A. Zürcher (TopAZ Embryotransfer, Lütisburg, Switzerland; personal communication) explained, a high incidence of cows with pathologic position of labia occurred in Switzerland between 1995 and 2010 due to use of bulls with the corresponding characteristics. Unfortunately, urovagina can only be diagnosed by rectal examination by a veterinarian (Bühler and Maurer, 2004). To prevent impaired fertility resulting from urovagina, a conformation trait that can be scored noninvasively by farmers, or at least by experts, with a high correlation to urovagina may be useful; position of labia might be such a trait.

\section{Heritability of Fertility Traits}

Cow fertility is a complex trait that has a major effect on the overall economic viability of dairy production (DeVries et al., 2005). One important component of fertility is the ability of a cow to return to the reproductive cycle after calving. To describe this, most authors used the time period between calving and first insemination (e.g., Berry et al., 2003; König et al., 2008). This time span is easy to calculate from AI data, but does not precisely describe the cow's ability to return to estrus, because farmers usually skip the first heat for AI. A more exact way to assess the onset of estrus is by activity measurements (Løvendahl and Chagunda, 2009) or by the progesterone concentration in milk (Royal et al., 2002). Although heritabilities for the trait time to first insemination in general were low $(<0.10)$, direct measurements of the time to first estrus provide a slightly higher heritability (0.10 to 0.18 ; Table 2 ).

In this study, we reported estimates of variance components and genetic parameters (heritability, repeatability) for a set of traits related to behavior, conformation, and functional aspects of Brown Swiss dairy cattle. We also calculated accuracies of EBV for these traits.

\section{MATERIALS AND METHODS}

\section{Data}

To estimate genetic parameters of the different traits, a data set of 1,799 phenotyped cows was available. These cows belonged to 40 Swiss dairy herds with mean (SD) 32 (14) and range 13 to 70 cows per herd, and they were daughters of 469 sires, with mean (SD) 4 (8) and range 1 to 67 daughters per sire. A subset of these cows was also used in Kramer et al. (2013) to estimate genetic parameters for milk content traits. Phenotypes were collected between November 2009 and April 2011. Every farm was visited 5 times, and all animals present on the visiting day were evaluated. Thus, not all lactations but the actual lactations during the collection period were incorporated in the present study. Depending on the trait, up to 4 measurements for each trait per cow were available from different lactations. The following 8 phenotypes were recorded:

- General temperament was scored by farmers with codes between 1 (very nervous) and 5 (very calm) to describe the temperament that was shown by the cow within the herd environment as described by Juga (1996).

- Milking temperament describes the temperament of a cow during milking. It was also scored by farmers with codes between 1 (very nervous) and 4 (very calm) following Dickson et al. (1970).

- Aggressiveness is a binomial trait scored by farmers to describe if a cow behaves aggressive (0) or untroubled (1) toward herd mates.

- Rank order in the herd was scored by farmers with codes 1 for low rank, 2 for medium rank, and 3 for high rank.

- Milking speed describes the time that is needed to milk a cow. Farmers gave a subjective score between 1 (very slow milking) and 6 (very fast milking). This definition of milking speed gives a long-term impression of the time that is needed for milking a cow and is less influenced by milk yield of one specific test day.

- Udder depth is an objective measurement of the distance between udder base and hock in centimeters. Negative values describe an udder base below the hock; high values describe a tight and high udder. Measurement of udder depth was done by experienced persons from a research organization with a simple measurement tool that was constructed for this study.

- Position of labia is a new conformation trait suggested by Bühler and Maurer (2004). It was scored by experienced persons from a research organization with codes of 0 for vertical but oblique labia, 1 for vertical labia, 2 for labia $<50 \%$ horizontal, $3>50 \%$ horizontal, and 4 for sunken vulva (a low score is better). Bühler and Maurer (2004) found that cows with position of labia coded with 3 have a significantly lower $(P<0.05)$ nonreturn rate at 75 d than cows with code 1 (62.5 vs. $64.6 \%$ ).

- Days to first heat is the number of days between calving and the first heat after calving that was observed by the farmer. Neither technical equipment nor milk sample analyses (progesterone content) were used for detection of first heat. We did not choose the trait days from calving to first insemination, which would have been easily avail- 


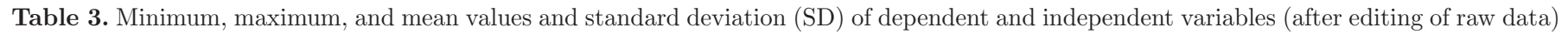
used for estimation of variance components

\begin{tabular}{|c|c|c|c|c|c|c|}
\hline Trait & $\mathrm{n}$ & Scale & Minimum & Maximum & Mean & $\mathrm{SD}$ \\
\hline \multicolumn{7}{|l|}{ Dependent variable } \\
\hline General temperament & 2,312 & Score & 1 & 5 & 3.53 & 0.99 \\
\hline Milking temperament & 2,259 & Score & 1 & 4 & 3.22 & 0.71 \\
\hline Aggressiveness & 2,309 & Binomial aggressive/quiet & 0 & 1 & 0.80 & 0.40 \\
\hline Rank order in herd & 2,304 & Score & 1 & 3 & 1.97 & 0.66 \\
\hline Milking speed & 4,540 & Score & 1 & 6 & 3.67 & 1.01 \\
\hline Udder depth & 2,195 & Centimeter above hock & -25 & 20 & 5.42 & 6.25 \\
\hline Position of labia & 2,232 & Score & 0 & 4 & 1.77 & 1.00 \\
\hline Days to first heat & 1,678 & Day & 12 & 134 & 46.26 & 23.41 \\
\hline \multicolumn{7}{|l|}{ Independent variable } \\
\hline Herd year season of calving & 480 & & & & & \\
\hline Age at first calving & 4 & Class & 1 & 4 & 2.55 & 1.18 \\
\hline Lactation number & 4 & Class & 1 & 4 & 2.70 & 1.54 \\
\hline DIM & & Day & 1 & 481 & 177 & 112 \\
\hline Milk yield in lactation & & Kilograms & 2,290 & 12,180 & 6,646 & 1,218 \\
\hline
\end{tabular}

able from AI data, because we thought that days from calving to first heat was closer to physiology. The smaller number of records for this parameter was due to difficulties in detecting the first heat just by visual observation.

One aim of our study was to evaluate the utility of data that can be collected by farmers during their routine daily work without any technical devices. For example, we used a simple scoring system for milking speed and not an exact measurement of milking speed in kilograms per minute, udder depth as a conformation trait that was easy to measure by a self-made tool, and no technical devices for detection of heat. Most of the farms used freestalls and only $20 \%$ used tiestalls. All tiestall herds had access to pasture in summer and to an outdoor yard in summer and winter, according to Swiss regulations. This guaranteed a regular (in most cases, daily) interaction between animals. Summary statistics of the available cow traits and independent variables are shown in Table 3. Before estimation of variance components, all records with DIM $>3$ SD above mean and milk yield per lactation $<3$ SD below mean were removed from the data set. Although the minimum of DIM is 1 , only traits such as general temperament were scored on the first days postpartum, which reflect a general assessment of the animal over a longer period. Measurements were taken only on d 20 or later. The 40 herds covered a wide range of extensive and intensive management representative for the Brown Swiss population in Switzerland. Maximum DIM (after data editing) was 481 in extensively managed herds and maximum lactation milk yield (after data editing) was $12,180 \mathrm{~kg}$ in intensively managed herds. Except for milking speed, none of the traits was routinely recorded but collected only within the framework of this study. From the complete pedigree, 4,208 animals of interest (phenotyped cows and bulls with high impact on the population) were extracted, for which EBV were predicted and the respective accuracies of EBV calculated.

\section{Model}

For estimation of genetic parameters of general temperament, milking temperament, rank order in herd, milking speed, udder depth, position of labia, and days to first heat, the following linear animal model was used:

$$
\begin{aligned}
y_{i j k l m n o}= & H Y S_{i j k}+A F C_{l}+\text { Lact }_{m}+b_{1} \text { DIM }_{i j k l m n o} \\
& +b_{2} \text { DIM }_{i j k l m n o}^{2}+b_{3} \text { MkgLact }_{i j k l m n o}+a_{n}+p_{n}+e_{i j k l m n o},
\end{aligned}
$$

and for the binary distributed trait aggressiveness, a linear logistic model was fitted (for details, see Koenig et al., 2005):

$$
\begin{aligned}
\log \left[\frac{\pi_{i j k l m n o}}{1-\pi_{i j k l m n o}}\right] & =H Y S_{i j k}+A F C_{l}+\text { Lact }_{m}+b_{1} \text { DIM }_{i j k l m n o} \\
& +b_{2} \text { DIM }_{i j k l m n o}^{2}+b_{3} \text { MkgLact }_{i j k l m n o}+a_{n}+p_{n},
\end{aligned}
$$

where $y_{i j k l m n o}=$ dependent variable (milking speed, udder depth, position of labia, rank order in the herd, general temperament, milking temperament, days from calving to first heat), $\pi_{i j k l m n o}=$ probability of a cow to be scored as aggressive, $H Y S_{i j k}=$ fixed effect of herd $i \times$ year of calving $j \times$ season of calving $k(i=1$ to $40, j=$ 1 to $3, k=1$ to 40$), A F C_{l}=$ fixed effect of age at first calving in months $(\leq 28,29-30,31-32, \geq 33)$, Lact $_{m}=$ fixed effect of lactation number $(1,2,3, \geq 4), D I M_{i j k l m n o}$ $=$ covariate days in milk, MkgLact ${ }_{i j k l m o}=$ covariate total milk yield in the lactation in which the measurement was done, $b_{1}$ to $b_{3}=$ linear regression coefficients 
for the covariates, $a_{n}=$ random additive genetic effect of animal $n, p_{n}=$ random permanent environment effect of animal $n$, and $e_{i j k l m n o}=$ random residual effect for observation $o$.

For random elements, the following distributions were assumed:

$$
\begin{aligned}
& \mathbf{a} \sim N\left(0, \mathbf{A} \sigma_{a}^{2}\right), \\
& \mathbf{e} \sim N\left(0, \mathbf{I} \sigma_{e}^{2}\right), \\
& \mathbf{p} \sim N\left(0, \mathbf{I} \sigma_{p}^{2}\right),
\end{aligned}
$$

where $\sigma_{a}^{2}$ is the additive genetic variance, $\sigma_{e}^{2}$ is the residual variance, $\sigma_{p}^{2}$ is the variance of permanent environment, $\mathbf{I}$ is an identity matrix, and $\mathbf{A}$ is the additive genetic relationship matrix.

Starting from the complete models above, PROC MIXED in SAS (SAS Institute, 2008) was used to identify all factors with significant $(P<0.05)$ influence on the observed trait by stepwise analysis. Only significant effects were included in the model used for estimation of genetic parameters (Table 4), which is a widely used strategy in multiple trait analyses (see Nielsen et al., 2005; König et al., 2006). We opted to test the effect of MkgLact because, according to Schutz and Pajor (2001), a farmer might, for example, be more patient with a high-yielding cow of bad temperament than with a low-yielding cow of bad temperament. This effect is better described by the amount of milk of the complete lactation than by the amount of milk of one test-day.

Estimation of genetic parameters and prediction of EBV were done with ASReml 3.0 (Gilmour et al., 2009). Genetic parameters for all traits were estimated in univariate analyses.

Heritabilities $\left(h^{2}\right)$ and repeatabilities $\left(w^{2}\right)$ for general temperament, milking temperament, rank order in herd, milking speed, position of labia, and days to first heat were derived from the variance components as follows:

$$
h^{2}=\frac{\sigma_{a}^{2}}{\sigma_{a}^{2}+\sigma_{p}^{2}+\sigma_{e}^{2}}
$$

and

$$
w^{2}=\frac{\sigma_{a}^{2}+\sigma_{p}^{2}}{\sigma_{a}^{2}+\sigma_{p}^{2}+\sigma_{e}^{2}},
$$

where $\sigma_{a}^{2}$ is the additive genetic variance, $\sigma_{p}^{2}$ is the variance of permanent environment, and $\sigma_{e}^{2}$ is the residual variance. Heritabilities and repeatabilities on the underlying liability scale for the binary trait aggressiveness were derived as (for details, see Koenig et al., 2005)

$$
h^{2}=\frac{\sigma_{a}^{2}}{\sigma_{a}^{2}+\sigma_{p}^{2}+\frac{\pi^{2}}{3}}
$$

and

$$
w^{2}=\frac{\sigma_{a}^{2}+\sigma_{p}^{2}}{\sigma_{a}^{2}+\sigma_{p}^{2}+\frac{\pi^{2}}{3}} .
$$

Accuracy $\left(\boldsymbol{r}_{T I}\right)$ of EBV was calculated as

$$
r_{T I}=\sqrt{1-\frac{S E^{2}}{(1+f) \sigma_{a}^{2}}},
$$

where $S E^{2}$ is the squared standard error of the EBV, $f$ represents the inbreeding coefficient (derived from the diagonal element of the additive genetic numerator relationship matrix), and $\sigma_{a}^{2}$ is the additive genetic vari-

\begin{tabular}{|c|c|c|c|c|c|c|c|c|c|}
\hline Item & $H Y S$ & $A F C$ & Lact & $D I M$ & $D I M^{2}$ & MkgLact & $a$ & $p$ & $e$ \\
\hline General temperament & $\mathrm{X}$ & & $\mathrm{X}$ & & & $\mathrm{X}$ & $\mathrm{X}$ & $\mathrm{X}$ & $\mathrm{X}$ \\
\hline Milking temperament & $\mathrm{X}$ & & $\mathrm{X}$ & & & $\mathrm{X}$ & $\mathrm{X}$ & $\mathrm{X}$ & $\mathrm{X}$ \\
\hline Aggressiveness & $\mathrm{X}$ & & $\mathrm{X}$ & $\mathrm{X}$ & & & $\mathrm{X}$ & $\mathrm{X}$ & \\
\hline Rank order in herd & $\mathrm{X}$ & $\mathrm{X}$ & $\mathrm{X}$ & $\mathrm{X}$ & $\mathrm{X}$ & $\mathrm{X}$ & $\mathrm{X}$ & $\mathrm{X}$ & $\mathrm{X}$ \\
\hline Milking speed & $\mathrm{X}$ & $\mathrm{X}$ & $\mathrm{X}$ & & & $\mathrm{X}$ & $\mathrm{X}$ & $\mathrm{X}$ & $\mathrm{X}$ \\
\hline Udder depth & $\mathrm{X}$ & $\mathrm{X}$ & $\mathrm{X}$ & $\mathrm{X}$ & $\mathrm{X}$ & $\mathrm{X}$ & $\mathrm{X}$ & $\mathrm{X}$ & $\mathrm{X}$ \\
\hline Position of labia & $\mathrm{X}$ & & $\mathrm{X}$ & & & & $\mathrm{X}$ & $\mathrm{X}$ & $\mathrm{X}$ \\
\hline Days to first heat & $\mathrm{X}$ & & & & & $\mathrm{X}$ & $\mathrm{X}$ & $\mathrm{X}$ & $\mathrm{X}$ \\
\hline
\end{tabular}
ance of the specific trait estimated from the data. The formula above was based on Misztal and Wiggans (1988), and $\sigma_{a}^{2}$ was multiplied by $(1+f)$ as suggested by Jamrozik et al. (2000) to account for inbreeding.

Table 4. Effects selected for evaluated traits: herd-year-season of calving ( $H Y S)$, age at first calving $(A F C)$, lactation number (Lact) DIM at day of sampling (DIM), lactation milk yield ( MkgLact), additive genetic effect $(a)$, permanent environment effect $(p)$, and residual effect $(e)^{1}$

${ }^{1} \mathrm{X}$ indicates that the effect was significant $(P<0.05)$ and included in the model for a given trait. 
Table 5. Additive genetic variance $\left(\sigma_{a}^{2}\right)$, permanent environment variance $\left(\sigma_{p e}^{2}\right)$, residual variance $\left(\sigma_{e}^{2}\right)$, heritability $\left(h^{2}\right)$, and repeatability $\left(w^{2}\right)$, with their standard error (SE), mean accuracy of EBV for all 4,208 animals in the data set $\left(r_{T I}\right.$ All), for phenotyped cows $\left(r_{T I}\right.$ Cows), and for 30 bulls with at least 10 phenotyped daughters in the data set ( $r_{T I}$ Bulls) from univariate analysis

\begin{tabular}{|c|c|c|c|c|c|c|c|c|}
\hline Trait & $\sigma_{a}^{2} \pm \mathrm{SE}$ & $\sigma_{p e}^{2} \pm \mathrm{SE}$ & $\sigma_{e}^{2} \pm \mathrm{SE}$ & $h^{2} \pm \mathrm{SE}$ & $w^{2} \pm \mathrm{SE}$ & \multicolumn{3}{|c|}{$r_{T I}$} \\
\hline General temperament & $0.36 \pm 0.07$ & $0.16 \pm 0.06$ & $0.41 \pm 0.02$ & $0.38 \pm 0.07$ & $0.56 \pm 0.03$ & 0.49 & 0.67 & 0.83 \\
\hline $\begin{array}{l}\text { Aggressiveness } \\
\text { (underlying liability scale) }\end{array}$ & $0.62 \pm 0.46$ & $1.13 \pm 0.46$ & & $0.12 \pm 0.08$ & $0.32 \pm 0.02$ & 0.27 & 0.34 & 0.52 \\
\hline Rank order in herd & $0.06 \pm 0.02$ & $0.09 \pm 0.02$ & $0.21 \pm 0.01$ & $0.16 \pm 0.06$ & $0.42 \pm 0.03$ & 0.39 & 0.51 & 0.70 \\
\hline Position of labia & $0.26 \pm 0.06$ & $0.05 \pm 0.05$ & $0.62 \pm 0.03$ & $0.28 \pm 0.06$ & $0.33 \pm 0.04$ & 0.45 & 0.62 & 0.79 \\
\hline Days to first heat & $8.33 \pm 19.02$ & $95.02 \pm 29.84$ & $338.05 \pm 24.47$ & $0.02 \pm 0.04$ & $0.23 \pm 0.05$ & 0.15 & 0.19 & 0.31 \\
\hline
\end{tabular}

Pearson correlations between EBV were calculated by PROC CORR in SAS (SAS Institute, 2008) to evaluate the dependency between the different traits.

\section{RESULTS AND DISCUSSION}

Estimates of additive genetic variance, permanent environment variance, residual variance, heritability, reliability, and accuracy of EBV of different groups of animals for the functional traits from univariate analyses are listed in Table 5. In general, heritability estimates were in good accordance with heritability estimates from literature for similar traits (Table 1 and Table 2). Correlations between all breeding values are presented in Table 6 . Absolute values of breeding value correlations varied in a wide range from 0.00 for the correlation between rank order in herd and general temperament to $0.49 \pm 0.01$ for the correlation between rank order in herd and aggressiveness.

\section{Genetic Parameters of Behavioral Traits}

We estimated low to moderate heritabilities for behavioral traits. We estimated the highest heritability of $0.38 \pm 0.07$ for general temperament, whereas milking temperament had a heritability of $0.04 \pm 0.04$. Rank order in herd had a heritability of $0.16 \pm 0.06$, and the binary trait aggressiveness had a heritability of $0.12 \pm$ 0.08 . For the binary trait aggressiveness, the heritability on the observed scale is about half the value obtained on the underlying scale (Dempster and Lerner, 1950). We also found moderate to high repeatabilities of the behavior traits of $0.56 \pm 0.03,0.32 \pm 0.04,0.32 \pm$ 0.02 , and $0.42 \pm 0.03$ for general temperament, milking temperament, aggressiveness, and rank order in herd, respectively. Heritability estimates for behavioral traits in dairy cattle are rare. Behavioral traits are often subjectively scored, are defined in different ways and on different scales, and are scored either by the farmer or by an independent person (Table 1). This fact makes it difficult to compare heritabilities of behavioral traits from different studies. In our study, all behavioral traits were scored by the farmers, and thus reflect a long-term impression of how a cow behaves in the milking parlor or during handling, so that the random error may be reduced. If, on the other hand, behavior is scored by an independent person in a unique testing situation (e.g., Hoppe et al., 2010; Sewalem et al., 2011), just one selective event during the time when scoring was done is described. Consequently, heritabilities of dairy cattle behavioral traits (Table 1) scored by farmers are on average higher (heritabilities around 0.20) than those

Table 6. Correlations ( \pm SE) between breeding values of the different traits

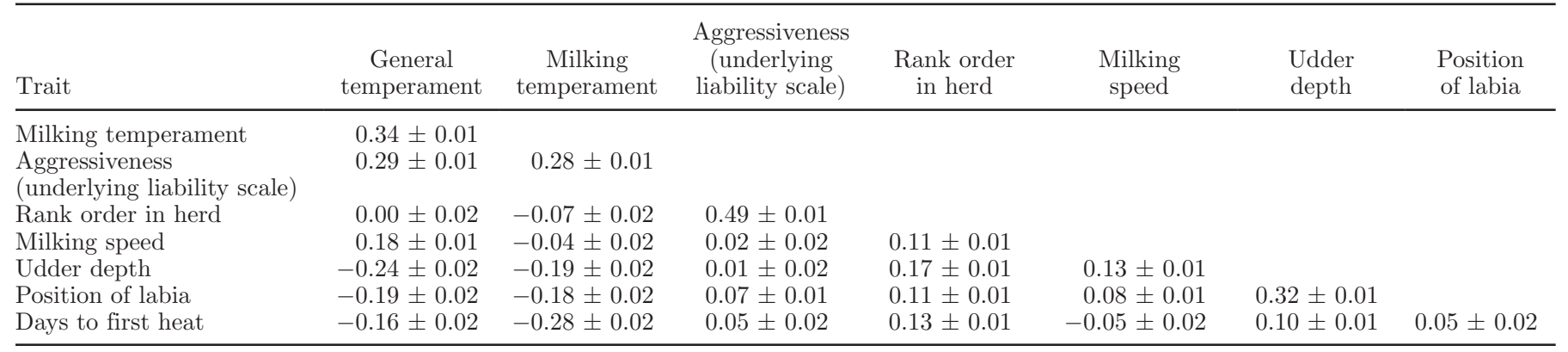


scored by independent persons (heritabilities around $0.12)$.

Heritability values for the 2 apparently similar traits general temperament and milking temperament were very different $(0.38 \pm 0.07$ vs. $0.04 \pm 0.04)$. This is in line with the literature, where mostly low heritabilities $<0.10$ were reported for milking temperament and moderate heritabilities between 0.12 and 0.25 were found for general temperament (Table 1). Our heritability estimate for general temperament was at the upper end, whereas that for milking temperament was at the lower end of values reported in literature. Hoppe et al. (2010) found a wide range of heritability estimates between 0.11 and 0.36 for the temperament trait flight speed score in different beef cattle breeds (Table 1). The divergence of our results obtained for Brown Swiss cattle from the results of other dairy cattle studies conducted mostly in Holsteins may also reflect a breed difference.

Another trait related to behavior or workability is aggressiveness. In our study, we estimated a heritability on the underlying liability scale of $0.12 \pm 0.08$ for aggressiveness observed as a binary trait, which was at the lower limit compared with values reported in literature. In dairy cattle, Sullivan and Burnside (1988) found a heritability of 0.11 for aggressiveness during feeding on a scale of 1 to 9. Le Neindre et al. (1995) estimated a heritability of 0.22 for docility in beef cattle (scale from 6.5 to 17), which can be considered the opposite of aggressiveness and thus should have similar heritability (Table 1). The different scales (observed scale of 1 to 9 or 6.5 to 17 , underlying liability scale) and different trait definitions (aggressiveness during feeding, docility, aggressiveness in general) make it difficult to compare our work with results from the literature.

The rank order of a cow in the herd is a trait that reflects the way an animal behaves in a social context. Rank order is a very complex trait and strongly influenced by age and weight of the individual, age of the herd mates, and interactions between them (Dickson et al., 1970). As described by Beilharz and Zeeb (1982), whether a cow is horned or dehorned also has an influence on rank order. This makes it difficult to estimate valid genetic parameters and might explain the lack of literature on genetic parameters of rank order. Herds in our study were either horned or dehorned, and most herds were dehorned. At most, 2 of the dehorned herds had single horned cows. Therefore, we believe that the effect of horned or dehorned cows did not influence our results. With this background, we estimated a relatively high heritability of rank order in herd of $0.16 \pm 0.06$.

In our study, behavioral traits were scored by farmers in relatively small herds (32 \pm 14 cows/herd). This had both advantages and disadvantages for parameter estimation. On the one hand, farmers handle their cows at least twice a day (during milking). Hence, they know each animal very well and should be able to give a realistic assessment of a cow's behavior. On the other hand, behavior scoring might be biased by a general assessment of a cow's quality and performance. Farmers are also less experienced in scoring cows on a standardized scale than independent experts are, and so might not use the full range of the scale properly. The high heritability estimates with low standard error we found for behavioral traits suggest that the advantages of farmer's scores on small farms outweigh the disadvantages. Our results seem to indicate that farmers are not more lenient with high-yielding cows of bad temperament compared with low-yielding cows of bad temperament. Results from other studies showed that an objective measurement of behavior leads to much higher heritabilities. Nkrumah et al. (2007) estimated a heritability of 0.49 for flight speed, with an objective measurement in meters per second. This is almost twice the heritability for flight speed estimated by Hoppe et al. (2010) on a subjective scale of 1 to 4 . This indicates that more work should be done to develop methods for objective measurement of behavior phenotypes, which may yield higher heritabilities and breeding values of higher accuracy.

Correlations of breeding values for the behavioral traits varied between $-0.07 \pm 0.02$ for the correlation between rank order in herd and milking temperament and $0.49 \pm 0.01$ for the correlation between rank order in herd and aggressiveness (Table 6). Compared with correlations between other studied traits (e.g., milking speed and position of labia or aggressiveness and udder depth), the correlations between the behavioral traits were high. This shows that the same trait complex (behavior) was always described by the breeding values. However, the correlations between these behavior traits were still low enough that the traits have to be considered as different traits.

\section{Genetic Parameters of Milking Speed}

Another farmer-scored trait on a subjective scale of 1 to 6 in our study was milking speed, for which we estimated a heritability of $0.42 \pm 0.06$ (Table 5). On the one hand, this heritability is at the high end for subjectively scored milking speed. In other studies, this trait showed a low to moderate heritability between 0.10 and 0.25 (e.g., Ilahi and Kadarmideen, 2004; Rensing and Ruten, 2005; Table 2). On the other hand, our heritability estimate is close to those from objectively measured milking speed (0.28-0.48; Table 2). Different factors explain the discrepancies between our findings and results in the literature. As mentioned by Ilahi and 
Kadarmideen (2004), the heritability of a trait that is measured on a continuous scale $(\mathrm{kg} / \mathrm{min}$ for milking speed) is usually higher than the heritability of a trait measured on a discrete scale, because information is lost when a continuous measurement is transformed into a few discrete classes. This partly explains the different heritabilities between subjectively scored and objectively measured milking speed in the literature. As mentioned in the context of behavioral traits, farmers are less experienced with scoring and so they might not use the full range of the scale. For milking speed, this is supported by Ilahi and Kadarmideen (2004), who noted that more than $60 \%$ of the cows received the intermediate code 3 for milking speed when scoring was done on a subjective scale of 1 to 5 . To prevent this instinctive preference of the mean value by the scorers, a scale of 1 to 6 is used in Switzerland. Swiss farmers are also experienced in scoring milking speed of their cows because breeding value estimation for milking speed in Switzerland has been based on these data for years. This might explain the close-to-normal distribution of scores in our study. This idea is supported by the work of Boettcher et al. (1998), who suggested that the scoring system for milking speed was applied more accurately by farmers when it was newly introduced. This led to a higher heritability for milking speed in the study of Meyer and Burnside (1987) of 0.21, whereas Boettcher et al. (1998) estimated a heritability of just 0.15 from farmer-scored milking speed with the same scoring system and for the same population of cows 11 yr later. Lassen and Mark (2008) found heritabilities of milking speed in tiestalls to be higher than those in freestalls. They explained this finding by the fact that farmers know their cows better in tiestalls, resulting in a better differentiation between cows and fewer pedigree errors due to fewer errors in documentation of AI. Pedigree errors lead to smaller additive genetic variance and therefore to smaller heritability estimates. Better knowledge of the individual cows is also true for small herds, as in our study, and could explain the high heritability we estimated. Our findings for milking speed suggest that it is also possible to describe a phenotype on a discrete and subjective scale with high accuracy if the scale is used assiduously. Consequently, the heritability of these traits is also high. The assiduous use of the scale by the farmers is also reflected by the relatively high repeatability of milking speed of 0.64 \pm 0.02 (Table 5). This indicates that farmers have the same mean and variance in mind when scoring cows and so gave the same score if a cow was evaluated a second time. Breeding values for milking speed showed the lowest absolute correlations $(0.02 \pm 0.02$ for aggressiveness to $0.18 \pm 0.01$ for general temperament) with all other traits of our study (Table 6).

\section{Genetic Parameters of Conformation Traits}

The objective measurement of udder depth $(\mathrm{cm}$ above hock) in our work may also explain the relatively high heritability of $0.42 \pm 0.06$ we estimated for this trait (Table 5). On a discrete scoring scale, udder depth is a trait of moderate heritability around 0.30 (Table 2 ). The official Swiss breeding value estimation system (Interbull, 2012) uses a heritability of 0.32 for udder depth (Table 2) scored on a scale of 1 to 9. Seykora and McDaniel (1985) estimated a heritability of 0.52 from exact measurement of udder height. Lassen and Mark (2008) estimated heritabilities for different conformation traits. Although most traits scored on a scale of 1 to 9 have moderate heritabilities (between 0.20 and $0.30)$, stature was measured in centimeters and had a heritability of 0.56 . Our results and these findings of Seykora and McDaniel (1985) and Lassen and Mark (2008) support the statement of Ilahi and Kadarmideen (2004) that objective measurements on a continuous scale lead to higher heritabilities. The continuous scale and exact measurement (centimeters above hock) also led to the highest repeatability in our study for udder depth of $0.71 \pm 0.02$ (Table 5).

For position of labia as a second conformation trait, we estimated a heritability of $0.28 \pm 0.06$ (Table 5). To our knowledge, this is the first study in which genetic parameters for this trait have been estimated, so there are no estimates in the literature for comparison. The value is in the same range as heritability estimates for other conformation traits related to connective tissue, such as udder attachment, rear udder attachment height, rear udder attachment width, and median suspensory of $0.23,0.28,0.21$, and 0.23 , respectively (Neuenschwander et al., 2005). The low repeatability $(0.33 \pm 0.04$, Table 5$)$ of the trait position of labia could be due to the high variability of this trait depending on stage of estrus cycle (A. Zürcher, TopAZ Embryotransfer, Lütisburg, Switzerland, personal communication). It was surprising to us that position of labia had a relatively strong breeding value correlation with udder depth of $0.32 \pm 0.01$ (Table 6). On the one hand, a high distance between udder and hock represents a tight udder and high quality connective tissue. On the other hand, a high score for position of labia represents a weak connective tissue around labia. Nevertheless, position of labia appears to be an interesting new phenotype and more work should be done to investigate the phenotypic and additive genetic correlation between urovagina and position of labia.

\section{Genetic Parameters of Fertility Traits}

The trait number of days from calving to first heat, as a trait that reflects the ability of a cow to return to 
estrus after calving, was practically not heritable $\left(h^{2}\right.$ $=0.02 \pm 0.04)$. Days to first heat also had the lowest repeatability in our work of just $0.23 \pm 0.05$ (Table 5). Correlations of days to first heat with other traits were mostly weak (Table 6). Other authors usually used a similar trait, interval from calving to first insemination (Table 2), and also estimated low heritabilities, between 0.02 (Berry et al., 2003) and 0.11 (Royal et al., 2002). The official Swiss breeding value estimation system (Interbull, 2012) uses a heritability of 0.04 for the interval from calving to first insemination (Table 2). In dairy cattle breeding schemes, dates of calving and AI are available with high reliability and at low cost, so days from calving to first insemination is a trait that is easy to calculate. At the same time, the date of first insemination is strongly influenced by farm management decisions, when, for example, high-yielding cows are inseminated later, and cows may be inseminated late because of seasonal calving (Andersen-Ranberg et al., 2005) or because a heat is overlooked. For this reason, the interval from calving to first heat, as used in our study, better reflects the cow's ability to return to estrus after calving than does the number of days to first insemination. Heat detection by visual observation only, as done in our study, is labor intensive and heats, particularly during the night, might not be noticed. Therefore, other traits that are closer to the physiological background, such as progesterone concentration in milk (Royal et al., 2002) or activity measured by a technical device (Løvendahl and Chagunda, 2009), can be used to detect heat. Progesterone concentration and activity showed heritabilities around 0.20 (Table 2), a value almost twice that for days to first heat or days to first insemination. It has to be considered that progesterone concentration or activity are just auxiliary traits for the trait of interest (days from calving to first heat). The utility of a correlated trait also depends on the additive genetic correlation between the auxiliary trait and the trait of interest.

\section{Accuracies of EBV}

The differences in heritability and number of measurements were also reflected in accuracies of $\mathrm{EBV}\left(r_{T I}\right)$ for the different traits (Table 5). Milking speed was a trait with high heritability for which the largest number of phenotypic measurements was available (Table 3 ). This led to the highest $r_{T I}$ of 0.53 if all animals were considered. Bulls with at least 10 daughters in the data set ( $\mathrm{n}=26$ bulls) had an average $r_{T I}$ for milking speed of 0.86 , which is close to the $r_{T I}$ achieved by proven sires for some traits. The lowest $r_{T I}$ of $0.15,0.19$, and 0.31 as an average of all animals, cows with phenotypes, and bulls with at least 10 daughters in the data set, respectively, were achieved for days to first heat. This was mostly due to a small heritability with high $\mathrm{SE}$ of $0.02 \pm 0.04$ (Table 5).

For most traits, the advantage in $r_{T I}$ of bulls with many daughters was small relative to $r_{T I}$ of EBV that were based on cow phenotypes (12 to 19\%). This finding might be advantageous in the future when functional traits will be implemented in genomic breeding programs. The benefit of genomic selection for low heritable functional traits is expected to outperform the benefit for production traits (König and Swalve, 2009; König et al., 2009). Such a genomic selection scheme will be based not only on genomic data of progenytested bulls, but also on genomic data of phenotyped cows. Especially for newly introduced phenotypic traits, the training set will be composed predominantly of a limited number of phenotyped cows, as in our study.

\section{CONCLUSIONS}

Our results showed that it is worthwhile to expend more effort in a differentiated phenotype collection because higher heritabilities, and consequently EBV of higher accuracy, can be achieved with a limited number of phenotyped cows. This extra effort can involve differentiated recording of various aspects of a trait complex such as behavior, assiduous use of a subjective scoring system (milking speed on a scale of 1 to 6 ), or an objective measurement of a trait (e.g., udder depth in centimeters above hock). We showed that EBV for the considered traits for phenotyped cows and for bulls with several phenotyped daughters can be estimated with reasonable accuracy. We believe that using these EBV (or quantities derived thereof such as deregressed proofs or daughter yield deviations) based on a limited number of phenotyped as quasi-phenotypes will allow genomic predictions to be established for novel functional traits.

\section{ACKNOWLEDGMENTS}

The authors gratefully acknowledge co-funding from the European Commission, under the Seventh Framework Program for Research and Technological Development, for the Collaborative Project LowInputBreeds (grant agreement no. 222623). However, the views expressed by the authors do not necessarily reflect the views of the European Commission, nor do they in any way anticipate the Commission's future policy in this area.

\section{REFERENCES}

Andersen-Ranberg, I. M., G. Klemetsdal, B. Heringstad, and T. Steine. 2005. Heritabilities, genetic correlations, and genetic change 
for female fertility and protein yield in Norwegian dairy cattle. J. Dairy Sci. 88:348-355.

Beilharz, R. G., and K. Zeeb. 1982. Social dominance in dairy cattle. Appl. Anim. Ethol. 8:79-97.

Berry, D. P., F. Buckley, P. Dillon, R. D. Evans, M. Rath, and R. F. Veerkamp. 2003. Genetic relationships among body condition score, body weight, milk yield, and fertility in dairy cows. J. Dairy Sci. 86:2193-2204.

Boettcher, P. J., J. C. M. Dekkers, and B. W. Kolstad. 1998. Development of an udder health index for sire selection based on somatic cell score, udder conformation, and milking speed. J. Dairy Sci. 81:1157-1168.

Bühler, A., and R. Maurer. 2004. Einfluss ausgewählter Exterieurmerkmale auf die Fruchtbarkeit beim Milchvieh. Diplomathesis SHL Zollikofen, Switzerland.

Dempster, E. R., and I. M. Lerner. 1950. Heritability of threshold characters. Genetics 35:212-236.

DeVries, A., J. vanLeeuwen, and W. Thatcher. 2005. Economics of improved reproductive performance in dairy cattle. Department of Animal Science, Florida Cooperative Extension Service, Institute of Food and Agriculture Science, University of Florida, Gainesville. Accessed Aug. 20, 2012. http://edis.ifas.ufl.edu/an156.

Dickson, D. P., G. R. Barr, L. P. Johnson, and D. A. Wieckert. 1970 Social dominance and temperament of Holstein cows. J. Dairy Sci. 75:904-907.

Gautam, G., and T. Nakao. 2009. Prevalence of urovagina and its effects on reproductive performance in Holstein cows. Theriogenology 71:1451-1461.

Gilmour, A. R., B. J. Gogel, B. R. Cullis, and R. Thompson. 2009. ASReml User Guide Release 3.0. VSN International Ltd., Hemel Hempstead, UK.

Hoppe, S., H. R. Brandt, S. König, G. Erhardt, and M. Gauly. 2010. Temperament traits of beef calves measured under field conditions and their relationships to performance. J. Anim. Sci. 88:19821989.

Ilahi, H., and H. N. Kadarmideen. 2004. Bayesian segregation analysis of milk flow in Swiss dairy cattle using Gibbs sampling. Genet. Sel. Evol. 36:563-576.

Interbull. 2012. Description of National Genetic Evaluation Systems for dairy cattle traits as applied in different Interbull member countries. Accessed Sep. 29, 2012. http://www-interbull.slu.se/ national_ges_info2/begin-ges.html.

Jamrozik, J., L. R. Schaeffer, and G. B. Jansen. 2000. Approximate accuracies of prediction from random regression models. Livest. Prod. Sci. 66:85-92.

Juga, J. 1996. Evaluation methods of subjectively scored functional traits in Finland. Interbull Bull. 14:155-160.

Koenig, S., A. R. Sharifi, H. Wentrot, D. Landmann, M. Eise, and H. Simianer. 2005. Genetic parameters of claw and foot disorders estimated with logistic models. J. Dairy Sci. 88:3316-3325.

König, S., Y. M. Chang, U. U. von Borstel, D. Gianola, and H. Simianer. 2008. Genetic and phenotypic relationships among milk urea nitrogen, fertility, and milk yield in Holstein cows. J. Dairy Sci. 91:4372-4382.

König, S., F. Köhn, K. Kuwan, H. Simianer, and M. Gauly. 2006. Use of repeated measures analysis for evaluation of genetic background of dairy cattle behavior in automatic milking systems. J. Dairy Sci. 89:3636-3644.

König, S., H. Simianer, and A. Willam. 2009. Economic evaluation of genomic breeding programs. J. Dairy Sci. 92:382-391.

König, S., and H. H. Swalve. 2009. Application of selection index calculations to determine selection strategies in genomic breeding programs. J. Dairy Sci. 92:5292-5303.
Kramer, M., M. Erbe, B. Bapst, A. Bieber, and H. Simianer. 2013 Estimation of genetic parameters for individual udder quarter milk content traits in Brown Swiss cattle. J. Dairy Sci. 96:5965-5976.

Lassen, J., and T. Mark. 2008. Short communication: Genotype by housing interaction for conformation and workability traits in Danish Holsteins. J. Dairy Sci. 91:4424-4428.

Le Neindre, P., G. Trillat, J. Sapa, F. Menissier, J. N. Bonnet, and J. M. Chupin. 1995. Individual differences in docility in Limousin cattle. J. Anim. Sci. 73:2249-2253.

Løvendahl, P., and M. G. G. Chagunda. 2009. Short communication: Genetic variation in estrus activity traits. J. Dairy Sci. 92:46834688.

Meyer, K., and E. B. Burnside. 1987. Scope for a subjective assessment of milking speed. J. Dairy Sci. 70:1061-1068.

Misztal, I., and G. R. Wiggans. 1988. Approximation of prediction error variance in large-scale animal models. J. Dairy Sci. 71(Suppl. 2):27-32.

Neuenschwander, T., H. N. Kadarmideen, S. Wegmann, and Y. de Haas. 2005. Genetics of parity-dependent production increase and its relationship with health, fertility, longevity, and conformation in Swiss Holsteins. J. Dairy Sci. 88:1540-1551.

Nielsen, N. I., T. Larsen, M. Bjerring, and K. L. Ingvartsen. 2005. Quarter health milking interval, and sampling time during milking affect the concentration of milk constituents. J. Dairy Sci $88: 3186-3200$.

Nkrumah, J. D., D. H. Crews, J. A. Basarab, M. A. Price, E. K. Okine, Z. Wang, C. Li, and S. S. Moore. 2007. Genetic and phenotypic relationships of feeding behavior and temperament with performance, feed efficiency, ultrasound, and carcass merit of beef cattle. J. Anim. Sci. 85:2382-2390.

Rensing, S., and W. Ruten. 2005. Genetic evaluation for milking speed in German Holstein population using different traits in a multiple trait repeatability model. Interbull Bull. 33:163-166.

Royal, M. D., A. P. F. Flint, and J. A. Wooliams. 2002. Genetic and phenotypic relationships among endocrine and traditional fertility traits and production traits in Holstein-Friesian dairy cows. J. Dairy Sci. 85:958-967.

Rupp, R., and D. Boichard. 1999. Genetic parameters for clinical mastitis, somatic cell score, production, udder type traits, and milking ease in first lactation Holsteins. J. Dairy Sci. 82:2198-2204.

SAS Institute. 2008. Base SAS 9.2 Procedures Guide. SAS Institute Inc., Cary, NC.

Schutz, M. M., and E. A. Pajor. 2001. Genetic control of dairy cattle behavior. J. Dairy Sci. 84(E. Suppl.):E31-E38.

Sewalem, A., F. Miglior, and G. J. Kistemaker. 2010. Analysis of the relationship between workability traits and functional longevity in Canadian dairy breeds. J. Dairy Sci. 93:4359-4365.

Sewalem, A., F. Miglior, and G. J. Kistemaker. 2011. Short communication: Genetic parameters of milking temperament and milking speed in Canadian Holsteins. J. Dairy Sci. 94:512-516.

Seykora, A. J., and B. T. McDaniel. 1985. Heritability of teat traits and their relationships with milk yield, somatic cell count, and percent two-minute milking. J. Dairy Sci. 68:2670-2683.

Sullivan, B. P., and E. B. Burnside. 1988. Can we change the temperament in the dairy cow? Accessed May 14, 2012. http://cgil uoguelph.ca/pub/articles/temp.html.

Winter, P. 2009. Praktischer Leitfaden Mastitis. Parey Verlag, Stuttgart, Germany. 